\title{
The Convergent Structural Base of Sustainable Development in the 21st Century
}

\author{
Sergey Zhironkin ${ }^{1, *}$, Michal Cehlar ${ }^{2}$, and Vitaly Zhironkin ${ }^{1}$ \\ ${ }^{1}$ Siberian Federal University, 660075 Lida Prushinskaya St. 2, Krasnoyarsk, Russia \\ ${ }^{2}$ Technical University of Kosice, Faculty of Mining, Ecology, Process Control and Geotechnologies, \\ 042009 Letná, Kosice, Slovak Republic \\ ${ }^{3}$ National Research Tomsk Polytechnic University, 634050, 30 Lenina st., Tomsk, Russia
}

\begin{abstract}
Sustainable development is a symbiosis of technological and social progress, as well as responsible environmental management, should not rely on old industries that actively consume non-renewable natural resources, but on new, convergent-technological ones. In this paradigm, the environmental safety of future generations is formed by structural shifts in the economies of advanced countries caused by the expansion of technological convergence. Technological convergence - the result of accelerating scientific and technological progress in the 21 st century - has a transformative effect on the economies of developed countries, forming a new type of sectorial genesis. It is not related to the deepening of sectorial specialization or inter-industry cooperation within the framework of the evolution of basic technologies, but to the emergence of technologies of a fundamentally new type, formed as a result of the merger of know-how from different industries. The structural shifts arising from technological convergence do not have the historical analogues and forms of regulation developed by industrial policies of developed countries. The article outlines the key statements of the the impact of convergent technologies on the structural base of sustainable development.
\end{abstract}

\section{Introduction}

At present, a new type of extended reproduction, which is essentially over-intensive and connected with a new integration of factors of production in new combinations of technology, cooperation and division of labor are being developed the countries of advanced market economies [1]. Technological breakthroughs of the 21st century, new forms of capital attraction and institutions of innovation investment create prerequisites for modernization of the system of productive forces. In this process, the diffusion of convergent technologies is connected with modification of economic relations in investment, innovation, credit spheres, in industry production, and transformation of ownership relations. The combination of such processes of modification of economic relations in the reproduction sphere creates conditions for structural shift of a new type, in which the structural-forming factor is not creation and commercialization of new industry technologies, but their interaction.

* Corresponding author: zhironkin@inbox.ru 


\section{Materials and Methods}

Today, there is a prevailing technocratic approach to exploring the role of convergent technologies in the development of modern economy and disregard to the analysis of reproductive relations, through which technological convergence creates structuraltransformative productive forces and modifies economic relations. For example, technological convergence was initially the object of sociological research in the 1990s (M. Castells [2]). Later, M.C. Roco, W.S. Bainbridge [3] identified convergent technologies as a synergistic result of interaction between representatives of four spheres of industry science: nano- and computational technologies, genetic engineering, neuroscience. Since 2001 under the auspices of the National Science Foundation of the United States, the so-called NBICinitiative (nanotechnologies-biotechnology-IT-cognitive sciences) has been put forward, which denotes a convergent whole. The connection of technological convergence with the development of the national innovation system is seen as a connection of isolated trajectories of sectorial sustainable development [4], and as integration of innovative processes in basic and high-tech industries based on digitization (structural-and-technological convergence) [5].

The implementation of the conditions for the development of the reproductive process in technologically advanced countries leads to the fact that the structure of the economy begins to directly depend on the growth rate of production of intellectual products. These processes take it to a new level of capitalization and, consequently, research, production and market opportunities (Figure 1).

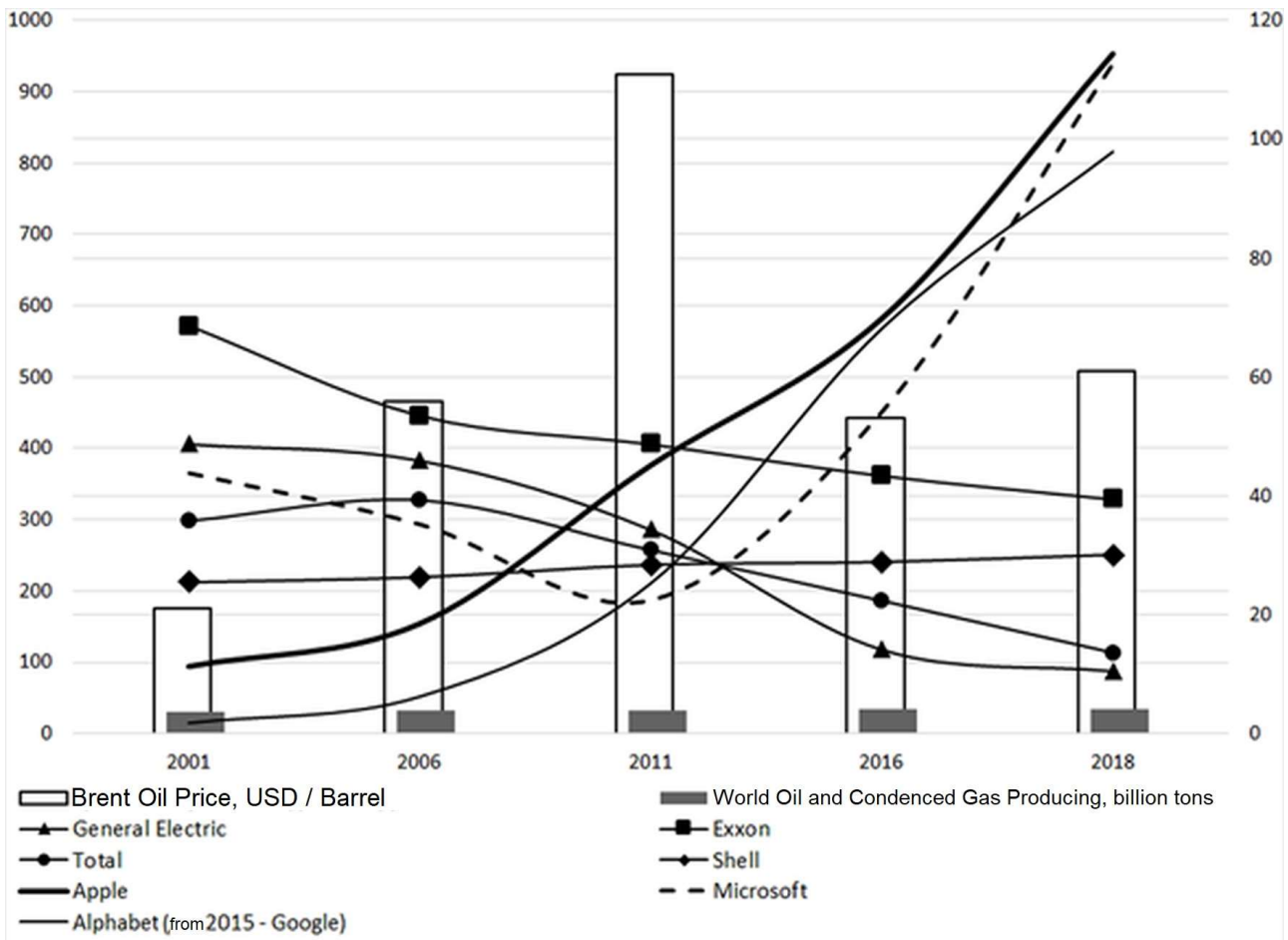

Fig. 1. The dynamics of the market capitalization of the largest international companies in the basic industries and the IT sector (annual average, billion dollars, left scale), oil prices and liquid hydrocarbon production volumes (right scale) [7] [8]. 
On the one hand, this is radically changing the structure of corporate property, employment and investment, and on the other, it accelerates and stabilizes macroeconomic dynamics. On the example of the United States, the trend of intellectualization and digitalization of the activities of the largest representatives of international business is clearly visible.

In terms of the development of productive forces, technological convergence means a new relocation of productive forces - both within production chains and spatially (including extraterritorial, in network form). As a result of this relocation, clusters of a new type are being formed, in which producers of the benefits of modern cycle of scientific and technological progress (such as modern medicines, global information access facilities, clean energy, etc.) create a "centric" network form of organization of the movement of resources, information and know-how, labour, and coordinate their activities on the basis of common economic incentives. Such relocation takes place in the form of the development of global network clusters of convergent technologies, using virtually unlimited sources of investment in the global capital market and a digital market for highly intelligent labour, creating products that exist mainly in intangible form, extraterritorially made and consumed.

\section{Results and Discussion}

Based on the above approaches to assessing the impact of convergent technologies on the development of national and global economy, we have highlighted the following principles of influence of convergent technologies on structural shifts:

1. The principle of accelerating the reproduction process during the expansion of converged technologies, according to which the connection of individual know-how and technological chains of different industries is accompanied by the connection of their investment flows.

2. The principle of the neo-industrial impact of technological convergence on the structural shift, according to which the separation of high-tech production from the innovative development of basic industries is unacceptable.

3. The principle of modification of economic relations in the system of public reproduction, connected with investment of innovations and their introduction, with creation of tax, financial and credit incentives of technological convergence, with acceleration of fixed capital renewal, with formation of new social relations and patterns of economic behavior.

4. The principle of targeted programming of convergent technologies development and investment in their mass production, diffusion in the basic sector of economy.

5. The principle of socializing technological convergence and smoothing out the negative consequences of the resulting structural shift.

The driving forces of technological convergence, such as modification of investment and change of nature of work in the process of development of fundamental research in the fields of NBIC, connection of the market of modern means of production and intellectual capital, transformation of property relations within the framework of collective investments, innovative entrepreneurship, public-private partnership in innovation define a set of conditions of influence of convergent technologies on structural shifts:

- reproduction and cluster conditions, which consist in accelerating the reproduction of fixed capital in modern manufacturing industries (mechanical engineering, radio electronics, production of synthetic materials and modern alloys, medicine, etc.).

- innovation and investment conditions of effect of convergent technologies on structural shifts are connected with neo-industrial development and modernization of industry, which should guarantee demand for NBIC-convergence products in the process of formation of post-oil energy (super-powerful power sources, bio-generators, etc.), technologies of 
superconductivity, recycling and energy-minimized industry, biochemical materials, nanocomputers.

- institutional conditions include purposeful development of state and business institutions capable of reorienting investment, labor, and intellectual resources from extractive and manufacturing industries to industries in which convergent technologies are created and find demand. This means that innovations generated in the fields of information, bio-, nano-, cognitive technologies should be demanded in the traditional industries - biochemistry, radio electronics, light, food industry, polymer production, etc.

- the social conditions of the impact of technological convergence on structural shifts imply the purposeful formation of a sustainable social group of convergent technology developers, innovative entrepreneurs and start-up managers.

Thus, the technological determinants of structural changes in the modern economy are represented not only by new technologies. They also include fundamentally new forms of reproductive relations, methods of production and consumption, as well as consumer preferences, individualizing as digitalization unfolds. It is important that with a personalized approach to production there is no rise in price of the product, as one would expect. On the contrary, the sustainable development approach allows optimizing costs as much as possible provided that the production processes are deeply automated, oriented towards the maximum rational use of technical resources, efficient energy conservation and environmental management.

\section{Conclusion}

Technological determinants of the structural shift (radical irreversible changes in macroand mesoeconomic proportions) can be considered those phenomena in the reproductive system that mediate the penetration of technologies into the processes of creation, distribution and consumption of goods, changing the picture of the involvement of production factors.

Firstly, inter-industry transfers and the international diffusion of innovations that generate technological convergence and create a synergistic effect of global scientific and industrial cooperation. The difference between the latter and the formation of global chains of movement of primary resources in the twentieth century. is the gain of all countries participating in innovative and technological cooperation, in contrast to the nonequivalent use of the raw materials potential of developing countries.

Secondly, the decentralization of production processes, their maximum automation and integration, focus on minimizing the share of material and natural resources.

Thirdly, the individualization of the manufactured product and the connection to the network of as many devices as possible (Internet of things, industrial Internet).

Fourth, the convergence of cognitive and information technologies, as well as nanotechnologies with their characteristic principle of suprasectoral functioning and a high level of integration potential.

Fifth, the shift in emphasis in basic research from the analysis of substances and processes to the synthesis of fundamentally new materials with new properties and characteristics. Their further construction at the atomic level with a reduction in the time gap between laboratory studies, the commercialization of innovations from 8-10 years in 1970-80 up to 23 years with access to a lower level of investment risk of innovation.

For the Russian economy, a positive technologically induced structural shift is the only way to reduce the technological gap. This in turn requires a review of the role of the state in regulating national reproduction. It is necessary to expand his partnership with high-tech business, creating maximum incentives for the inter-industry transfer of innovation and investment in convergent-technological production. 


\section{References}

1. S.A. Zhironkin, K.A. Kolotov, A.E. Genin, F.V. Agafonov, S.A. Kovalevsky, IOP Conf. Ser.: Earth Environ. Sci., 50:1, 012011 (2017)

2. M. Castells, P. Himanen, The Information Society and the Welfare State: The Finnish Model (Oxford University Press, Oxford, 2002)

3. M.C. Roco, W.S. Bainbridge, Converging technologies for improving human performance: nanotechnology, biotechnology, information technology and cognitive science (Kluwer Academic Publishers, New York, 2003)

4. A. Gate, University of Toronto Faculty of Law Review, 58:2, 83-117 (2000)

5. T. Strader, Digital Product Management, Technology and Practice: Interdisciplinary Perspectives: Interdisciplinary Perspectives (Business Science Reference, Hershey, 2011)

6. Top 10 most expensive companies in the world in 2019. Official website of the FXSSI news agency. URL: https://ru.fxssi.com/top-10-samyx-dorogix-kompanij-mira

7. Brent oil prices. The official website of the information and consulting agency RBC. Quotes section. URL: https://quote.rbc.ru/ticker/181206

8. L. Dube, A. Faber, J. Struben, K.J. Srivardhini, Annals of the New York Academy of Sciences, 13311:1, 144-159 (2014) 